\title{
DNA Metabarcoding of the Leachate Microbiota from Sanitary Landfill: potential for bioremediation process
}

\author{
Michel Passarini \\ Universidade Federal da Integracao Latino-Americana \\ João Moreira \\ Universidade Federal da Integracao Latino-Americana \\ Jose Alejandro Gomez \\ Universidade Federal da Integracao Latino-Americana
}

Rafaella Costa Bonugli-Santos ( $\square$ rafaellabonugli@gmail.com )

Universidade Federal da Integracao Latino-Americana https://orcid.org/0000-0002-5038-8491

\section{Research Article}

Keywords: Municipal solid waste, 16S rDNA, Next-generation sequencing, Prokaryote diversity, Biological treatment

Posted Date: April 5th, 2021

DOI: https://doi.org/10.21203/rs.3.rs-170197/v1

License: (c) (i) This work is licensed under a Creative Commons Attribution 4.0 International License. Read Full License

Version of Record: A version of this preprint was published at Archives of Microbiology on July 6th, 2021. See the published version at https://doi.org/10.1007/s00203-021-02471-8. 


\section{Abstract}

Microbial profile knowledge is essential to news alternatives and improvements in current treatments and destinations of landfill leachate that contains a variety of toxic compounds produced by municipal solid waste (MSW) disposal. Environmental DNA metabarcoding is an efficient, quick, and low-cost methodology for whole communities' characterization. In this respect, the leachate from the Sanitary Landfill of Foz do Iguaçu City showed mixed characteristics from both acid and methanogenic phases, and $16 \mathrm{~S}$ rDNA metabarcoding suggested the dominance of fermenting bacteria belonging to Firmicutes phylum, followed by Proteobacteria, Bacteroidetes and Synergistetes. The leachate acidogenic phase ended up being masked in the chemical and physical analyzes, however was evidenced in the metabarcoding methodology. On the other hand, no specifically methanogenic group was detected in significant abundance. To future application using culturomics approaches to bioremediation the leachate sample presented groups extensively studied, especially the Pseudomonas genus to heavy metals treatments, such as cadmium.

\section{Introduction}

Landfill leachate is a dark liquid with characteristic smell and high biochemical oxygen demand, produced by rainwater infiltration in municipal solid waste (MSW) cells and organic matter degradation [1]. Chemical, physical and microbiological processes on MSW degradation cause the release of pollutants to leachate [2]. Municipal landfill leachates must be considered wastewater with the highest environmental impact [3]. The leachate pollutant composition can be divided into four main groups: i) dissolved organic matter composed of volatile fatty acids and refractory compounds similar to fulvic and humic compounds; ii) inorganic macro components formed by calcium, magnesium, sodium, potassium, ammonium, iron, manganese, chloride, sulfide, and hydrogen carbonate; iii) heavy metals composed of cadmium, chromium, copper, lead, mercury, nickel, zinc; and iv) xenobiotic organic compounds present in low concentrations (less than $1 \mathrm{mg} \mathrm{L}^{-1}$ ), including aromatic hydrocarbons, phenols, aliphatic chain chlorines, pesticides, and plasticizers [2,3].

The lack of soil sealing and leachate drainage cause soil infiltration in dumps and controlled landfills. The leachate is then diluted in groundwater or nearby water bodies, generating contamination [4]. Although sanitary landfills are engineered to avoid potential leaking, it may occur eventually due to bad management, low-quality building materials and degradation of the geomembrane [1]. Leachate presence in water bodies and soil could disturb the present microbiota due to its acid or alkaline $\mathrm{pH}$ and toxic compounds [2].

To reduce the landfill leachate impact, a more efficient and inexpensive treatment must be developed to mitigate the effects caused to the environment and human health. For this reason, knowledge of microbial diversity is essential for bioremediation approaches development and optimization towards leachate. Knowing the microbial diversity associated with leachate enables the isolation methodologies for recovery of the specific microorganisms present in this process, improves knowledge for the bio- 
augmentation techniques, or environmental enrichment could be developed to metabolizing the toxic compounds present in these environments.

Next-generation sequencing made possible whole community characterization in landfills and leachate $[5,6]$. Although these studies have provided insight into the composition of resident microbial populations, the assessments remain incomplete. It is especially the case of stabilized leachate that shows low biodegradation efficiency and needs more biological investigations [7]. Thereby, the detection of the lowabundance microbial species might reveal further valuable information about the metabolic capabilities and adaptability of bacterial assemblages [8]. In this way, using 16S rRNA metabarcoding approaches, this research aimed at the microbiota characterization associated with leachate, with a recirculation system, from Foz do Iguaçu sanitary landfill. Knowledge of the microbiota was explored for especially to the future application using culturomics approaches to bioremediation process. Culturomics is the coupled application of omics-based tools, such as metagenomics or metabarcoding, to improve cultivation efficiencies of environmental microbiota [9].

\section{Materials And Methods}

\section{Sampling}

The sample was collected on May 15, 2019, from MSW cells (reservoir 1, which receives an influx of leachate) in the municipality of Foz do Iguaçu sanitary landfill Paraná, Brazil. Approximately $500 \mathrm{~mL}$ of leachate were collected in a minimum depth of one meter from laggon liquid storage, using a sterile glass bottle. The sample was transferred adequately to $50 \mathrm{~mL}$ sterile falcons and frozen at $-80^{\circ} \mathrm{C}$ for DNA preservation in the Laboratory of Biochemistry and Microbiology - UNILA. About $400 \mathrm{~mL}$ of leachate sent for physical-chemical analysis were kept at $4^{\circ} \mathrm{C}$.

Foz do Iguaçu sanitary landfill $\left(25^{\circ} 27^{\prime} 47.9^{\prime \prime} S 54^{\circ} 36^{\prime} 26.4^{\prime \prime} \mathrm{W}\right)$ is located in the city's northeast region. The landfill has a total area of $389.737,44 \mathrm{~m}^{2}$ and has three cells where the MSW is deposited, at the time of collection. Cells 1 and 2 have six layers of MSW each, and their area is $58.387,15 \mathrm{~m}^{2}$ and $61.584,01 \mathrm{~m}^{2}$, respectively. The MSW deposit on cell 1 began in 2001 until 2010, and cell 2 from 2010 to 2017). Cell 3 operation started in 2017, July, and comprises an area of $64.780,63 \mathrm{~m}^{2}$. Four reservoirs in the landfill receive an influx of leachate produced by MSW cells (supplementary material). The leachate was collected through the landfill drains and sent to liquid storage in a stabilization pond. It remained stored until recirculated, through pumping and sprinklers, in impervious areas within the landfill.

The sample was sent to TECLAB - Technologies in Laboratorial Analysis, for physical-chemical characterization. Levels of arsenic, cadmium, lead, copper, chrome, mercury (using atomic absorption and emission Spectroscopy), nitrates, nitrites, ammoniacal nitrogen, organic nitrogen, total nitrogen, dissolved oxygen, biochemical oxygen demand (BOD), chemical oxygen demand (COD) and pH were measured. The analyzes were performed in triplicate according to the company's protocol.

\section{$16 S$ amplicon library preparation and sequencing}


In the DNA extraction was necessary the sample concentration. Thus, $10 \mathrm{~mL}$ of leachate was centrifuged at $10.000 \mathrm{xg}$ for 25 minutes. The resulting supernatant was discarded, and the pellet was suspended with $250 \mu \mathrm{L}$ of deionized water. According to the manufacturer's instructions, total leachate community DNA was extracted from $10 \mathrm{~mL}$ of the sample by using the DNeasy® PowerSoil® kit (QIAGEN). The purity was checked, and the DNA integrity was confirmed by electrophoresis in a $0.8 \%$ agarose gel. DNA samples were stored at $-20^{\circ} \mathrm{C}$ until downstream analyses. BPI BIOTECNOLOGIA EPP, Botucatu-SP performed DNA amplification and sequencing. PCR reactions were executed with a final volume of $20 \mu \mathrm{L}$ containing $10 \mu \mathrm{L}$ of GoTaq ${ }^{\circledR}$ Colorless Master Mix 2x (Promega, USL), $0.3 \mu \mathrm{M}$ of forward oligonucleotide, $1 \mu \mathrm{L}$ of total genomic DNA and sterile ultrapure water. The $16 \mathrm{~S}$ region (V3 and $\mathrm{V4}$ ) of rRNA was amplified with the primer 5'-TCGTCGGCAGCGTCAGATGTGTATAAGAGACAGCCTACGGGNGGCWGCAG-3' [10]. Reactions were performed in a Veriti ${ }^{\mathrm{T}}$ Thermal Cycler (Applied Biosystems). After the amplification reaction, its efficacy was assessed through an electrophoresis essay with $2 \%$ agarose gel stained with UniSafe dye $0.03 \%(\mathrm{v} / \mathrm{v})$ where amplicons had $600 \mathrm{bp}$ in size. Indexation reaction was performed using Nextera XT Index kit (Illumina). Indexers used were N701 (TAAGGCGA) and S502 (ATAGAGAG). Generated libraries were purified using Agencourt AMPure XP (Beckman Coulter) magnetics beads. Quantification of the libraries were performed using RT-PCR KAPA-KK4824 kit (Library Quantification Kit -

Illumina/Universal). The equimolar DNA pool created was submitted for sequencing in an Illumina MiSeq (Illumina ${ }^{\circledR}$ Sequencing) with MiSeq Reagent Kit V2 Nano.

\section{Bioinformatic analysis of amplicon library sequences}

The Qiime2 - 2019.10 [11] pipeline and FastQC app compiled in Galaxy Europe [12] were used to analyze sequence data. The Qiime2 Taxa plugin was used for taxonomic attribution with $99 \%$ of identity against SILVA v132 [13] database. A bar plot graph was generated and processed, where genera with relative frequency under $0.5 \%$ were grouped in others categories. Alpha diversity was assessed using Qiime2 alpha diversity plugin, generating a rarefaction curve with 9000 sequences depth, using Shannon index, Simpson index, and Good's coverage.

\section{Results And Discussion}

\section{Leachate physical-chemical characterization}

Leachate composition may directly influence the microbial community richness, and it is essential to understand the environment. Table 1 shows the results of the sample's physical-chemical characterization, and the datas were used to identify the biological phase of our leachate. There are different phases during the biological degradation of solid waste. It begins in a hydrolytic phase and ends in a methanogenic phase. In the hydrolytic phase, the organic fraction can be metabolized aerobically to form $\mathrm{CO}_{2}$ and $\mathrm{H}_{2} \mathrm{O}$. The anaerobic phase is characterized by fermentation, which can generate organic acids and ammoniacal nitrogen. The formation of acetate and methane is carried out by the acidogenic and methanogenic phases, respectively [14]. Each phase has a direct impact on leachate composition. 
Young leachate has a considerable amount of biodegradable organic matter, mainly volatile fatty acids and high molecular weight compounds characterize old leachate [14].

The leachate showed $\mathrm{pH}$ (8.52), characteristic of the methanogenic phase according to National Environment Council [15]. The COD level was within the standard interval of a methanogenic phase [2]. On the other hand, the level of BOD was well below that reported for the methanogenic and acid phases, and the BOD/COD ratio was 0.58 , characteristic of the acidic phase [2]. Based on these results, it is possible to indicate that the sample had a mixed profile with traits from both acid and methanogenic phases, and good biodegradability. These data, together with the ammoniacal nitrogen concentration, are also used for characterization of landfill leachate with age [2]. Except for good biodegradability (BOD/COD ratio), all values indicate that our leachate is in a stabilized stage (typical in the methanogenic phase), more than 10 years [7], confirming the historical data of the Foz do Iguaçu sanitary landfill. The leachate reservoirs heterogeneousness by recirculation must have caused this variation the biodegradability and in the methanogenic phase with acidic characteristics.

Table 1. Physical-chemical analysis of leachate sampled in the sanitary landfill from Foz do Iguaçu, Paraná, Brazil. 


\begin{tabular}{|lllll|}
\hline Parameter & Result & Unit. & Q.L. & M.A.V. \\
\hline Arsenic & $<0.10$ & $\mathrm{mg} \cdot \mathrm{L}^{-1}$ & 0,10 & 0,5 \\
\hline Total cadmium & 0.048 & $\mathrm{mg} \cdot \mathrm{L}^{-1}$ & 0,005 & 0,2 \\
\hline Total lead & $<0.005$ & $\mathrm{mg} \cdot \mathrm{L}^{-1}$ & 0,005 & 0,5 \\
\hline Total copper & 0.120 & $\mathrm{mg} \cdot \mathrm{L}^{-1}$ & 0,005 & 1,0 \\
\hline Total chrome & 0.080 & $\mathrm{mg} \cdot \mathrm{L}^{-1}$ & 0,005 & 1,1 \\
\hline BOD/COD & 0.58 & - & - & $\mathrm{N} . \mathrm{E}$. \\
\hline BOD & $2.074,0$ & $\mathrm{mg} \cdot \mathrm{L}^{-1}$ & 2,0 & $\mathrm{~N} . \mathrm{E}$. \\
\hline COD & $3.599,0$ & $\mathrm{mg} \cdot \mathrm{L}^{-1}$ & 5,0 & $\mathrm{~N} . \mathrm{E}$. \\
\hline Mercury & $<0.01$ & $\mathrm{mg} \cdot \mathrm{L}^{-1}$ & 0,01 & 0,01 \\
\hline Nitrates & $<1.0$ & $\mathrm{mg} \cdot \mathrm{L}^{-1}$ & 1,0 & $\mathrm{~N} . \mathrm{E}$. \\
\hline Nitrites & 0.20 & $\mathrm{mg} \cdot \mathrm{L}^{-1}$ & 0,02 & $\mathrm{~N} . \mathrm{E}$. \\
\hline Ammoniacal nitrogen & 486 & $\mathrm{mg} \cdot \mathrm{L}^{-1}$ & 0,05 & 20,0 \\
\hline Organic nitrogen & 638 & $\mathrm{mg} \cdot \mathrm{L}^{-1}$ & 0,50 & $\mathrm{~N} . \mathrm{E}$. \\
\hline Total nitrogen & 1,125 & $\mathrm{mg} \cdot \mathrm{L}^{-1}$ & 0,50 & $\mathrm{~N} . \mathrm{E}$. \\
\hline Dissolved oxygen & 6.6 & $\mathrm{mg} \cdot \mathrm{L}^{-1}$ & 0,10 & $\mathrm{~N} . \mathrm{E}$. \\
\hline pH & 8.50 & - & - & $5-9$ \\
\hline
\end{tabular}

Note: N.E: Not Established; Q.L: Quantification Limit. M.A.V: maximum allowed value for effluent discharging [17].

Studies have shown that leachate recirculation produces stabilized leachates with good BOD/COD ratio [16]. Although a landfill may have most advanced leachate management practices, recycling process, in some researches, resulted in an imbalance between acidogenesis and methanogenesis in the landfill leachate $[17,18]$. The good BOD/COD ratio may mask a deficiency in the natural process. Thus, we believe that the specific knowledge of the microbiota can be a strategy for this issue.

The most of the nitrogen in aerobic and anaerobic landfill reactors is in the ammonia forms following the degradation of protein and amino acids [19]. Landfill leachate treatment generally focuses on the removal of organic nitrogenous, carbonaceous matter and ammonia nitrogen. Leachate from older landfill is rich in ammonia nitrogen due to hydrolysis and fermentation of the nitrogenous fraction of biodegradable substrates [20]. The variation of organics and ammonia nitrogen with time may have 
important implications in leachate treatment. Ammoniacal nitrogen concentration in our leachate was 0.66 times lower than the average value [2], a level that does not exert any adverse effect on anaerobic processes [21]. Although possibly characterized by a stabilized leachate, the efficiency in the removal of ammoniacal nitrogen is due to recirculation [22].

The total nitrogen concentration was 0.38 times lower than what was published by Gabarró et al. [23]. And, the presence of nitrite was detected, opposing what was reported by these authors. Nitrification is the process that converts ammonia to nitrite and then to nitrate and is an important step in the global nitrogen cycle; this step most occurs aerobically [24]. Also, the study of Kaczorek and Ledakowicz [25], about the kinetics of nitrogen removal from sanitary landfill leachate showed that the temporary accumulation of nitrite was observed too during the denitrification. The utilization rates of nitrate and nitrite were best fitted, taking into ac-count the limitation by nitrogen substrates [25], as noted in our case (low concentration of total nitrogen). In the leachate treatment, the ammonium conversion to nitrite was achieved and controlled by means of the available alkalinity [26]. These findings affirm the importance of $\mathrm{pH}$ for the bacterial activity of ammonia oxidizing bacteria, the maintenance of free ammonia (NH3) at favorable levels for nitrite accumulation, and the prevention of nitrite to nitrate oxidation [26]. This condition may justify the low ammonia value in our sample and efficient nitrogen conversion without a high percentage of nitrate. Concerning leachate recirculation and phase mixtures, according to Yang and Song [27] nitrification and denitrification mainly occurred at aerobic and methanogenic phase, what is possibly happening in the Foz do Iguaçu system. Regarding the presence of nitrate in the sample, it is an important highlight that these chemical compounds have significant solubility and are carried to water bodies through lixiviation resulting in their contamination [28].

The metal concentrations of landfill leachate are expected to reduce as the leachate changes from acidogenic to methanogenic, concurrent with a decrease in redox potential and an increase in $\mathrm{pH}$ [16]. But in our sample, even with high $\mathrm{pH}$, the cadmium concentration in the sample was 9.6 times higher than the literature standard. This inefficiency in removing cadmium, mainly, may be related to the imbalance caused by the recirculation. The copper level was too 1.84 times higher than the literature standard. This data is relevant to contamination, as some organisms absorb this metal, it is accumulated in the liver. It prevents its detoxification, allowing the increase of its concentration in different tissues and affecting the nervous system, reproductive system, connective tissues, adrenal functions, and several other complications [29].

\section{Microbial community, functional diversity and bioremediation potential}

A total of 40.705 reads were recovered from the leachate sample. Deduplication step resulted in 25.039 non-chimeric filtered reads (62\% of total). DNA sequences were grouped in 365 OTUs where 252 were taxonomically labeled. Good's estimation indicates a full coverage $(100 \%)$ of the microbiota present in the sample and rarefaction curve (Figure 1) showed an expressive coverage of the prokaryotic organisms,

given the curve plateau. That is suggesting the sampling was able to cover the prokaryote diversity of the 
sample. Shannon and Simpson's index (value 7.7 and 0.99, respectively) indicated a great and high diversity in the sample [30].

Metabarcoding revealed a considered high diversity represented by 29 different phyla (Figure 2 and supplementary material), 27 from Bacteria, and two from Archaea domain. Dominant phyla were Firmicutes (41.91\%), followed by Proteobacteria (20.90\%), Bacteroidetes (11.90\%) and Synergistetes (7.36\%). Euryarchaeota and Nanoarchaeota phyla from the Archaea domain had a relative frequency of $3.92 \%$ and $0.20 \%$, respectively. A total of 102 DNA sequences were affiliated to the Archaea phylum, representing only $0.41 \%$ of all identified sequences. However, proper quantification of archaeal diversity and community ecology remains limited, as sequence coverage of Archaea is usually low owing to the inability of available prokaryotic primers to efficiently amplify archaeal compared to bacterial rRNA genes [31]. In this sense, we seek to explore the bacterial community.

These results followed the same described in the Candeias young sanitary landfill [8] study by 454 pyrosequencing. The authors found a high microbial diversity: the abundance was represented by Firmicutes, the most abundant phylum followed by Proteobacteria, Bacteroidetes, Spirochaetes, Synergistetes, and Tenericutes phylum. Slight differences from our work may occur due to the landfill age gaps of six years. On the other hand, newer than our treatment system, the research of Khanh Son landfill, also using new generation sequencing, had as dominant phyla: Proteobacteria, Firmicutes, Bacteroidetes, and Euryarchaeota [30]. Like this, geographic and climate differences of landfill sites also have a decisive role in microbial composition.

The recent work performed by Yang and Son [27], reviewed microbial diversity studies based on the new generation sequencing. The authors concluded that Proteobacteria, Firmicutes, and Bacteroidetes were the dominant representatives, with variations between the relative abundance as described above. Their work showed that the phylum Firmicutes was highly representative of the anaerobic acid and aerobic phases. In contrast, the phylum Proteobacteria was very rare in the anaerobic acid phases, and the relative abundance of Bacteroidetes increased from aerobic to anaerobic acid phases. Comparing with our relative abundance, it is possible to indicate that due to recirculation, possibly the anaerobic acid phase may be suppressed in the treatment system of the city of Foz do Iguaçu. The microbial populations involved in the anaerobic acid phase act to covert hydrolysis substrate to methane metabolic precursors [27].

The effect of leachate recirculation was evaluated in the anaerobic digestion, using a bioreactor system, in the study of Luo and Wong [32]. The pH values of recirculated leachate were adjusted to 6.0 and 7.5, lower than that detected in the present study. Despite different conditions, the taxonomic profile of relative abundance identified was very similar to our work. Among them, Firmicutes was the dominant phylum during the whole anaerobic digestion process. Also, under the conditions of the study, the authors identified that the recirculation provides a straightforward approach to enhance the hydrolysis efficiency and, at the same time, biochemical balanced leachate to enhance methanogenic reaction. 
The vast majority of the dominant diversity found were anaerobic fermenting bacteria affiliated to Firmicutes phylum and Clostridiales order (supplementary material). Firmicutes phylum comprises many gram-positive bacteria, including pathogenic free-living bacteria, which have a great ecological diversity such as Actinobacteria [33]. This group is possibly the most contributed to the degradation of organic matter and xenobiotic compounds and the carbon cycle, besides given the ability to ferment a wide variety of recalcitrant organic compounds [34]. The MSW cells anoxic conditions favored this result. The abundance of Ruminiclostridium and Caldiprobacter genera implied a fundamental role in the vegetal organic matter fermentation, one of MSW main compounds [8]. This profile may be significantly related to the acidogenic phase of the leachate, which due to recirculation, ends up being masked in the chemical and physical analyzes.

Proteobacteria, the second phyla with the highest percentage of relative abundance (figure 2), is the greatest gram-negative phylum, divided into nine classes including pathogenic genera, including Escherichia, Salmonella, Vibrio, and Helicobacter [35]. It also contains many free-living genera and nitrifying bacteria. Pseudomonas genus belonged to this phylum had the most significant relative frequency among all identified genera, with 1.666 reads (figure 3). Pseudomonas genera are vastly employed on contaminated water bodies denitrification [36], and together with Thauera are capable of performing denitrification using nitrate or nitrite as electron acceptors.

Pseudomonas aeruginosa was described as resistant to cadmium, and it can absorb and accumulate it through a stress response [37]. Despite the high level of cadmium, its concentration did not surpass the maximum value established by CONAMA. Still, cadmium toxicity alters the cellular proliferation, division, and apoptosis processes and affects cellular respiration, inhibiting the mitochondria [38]. The toxicity of leachate against cadmium concentration should be investigated. And if positive, Pseudomonas aeruginosa, with a significant presence, can be explored for futures culturomics studies.

Regarding Bacteroidetes phylum, only the genus Proteiniphilum, an exclusively proteolytic genus [39], was identified (Figure 3). Its abundance suggests a role in the degradation of proteins present in the leachate and nitrification process. It is a genus of bacteria already known in urban waste treatment systems, on young and older systems [27].

The presence of sulfate-reducing bacteria indicates that the reductive pathway of the sulfur cycle may be present and in use [40]. Sulfur-reducing genera detected were Desulfobulbus, Desulfomicrobium, Desulfovibrio, Desulfuromonas, Geobacter, and Pelobacter, belonging to Proteobacteria phylum, and Desulfitibacter and Desulfuribacillus, belonging to Firmicutes phylum.

Our data showed many OTUs related to the phylum Synergistetes (figure 3), but with a low taxonomic identification level. Synergistetes is a recently recognized phylum of anaerobic bacteria that inhabit a majority of anaerobic environments, including animal gastrointestinal tracts, soil, oil wells, and wastewater treatment [41]. This phylum was identified from anaerobic membrane bioreactor treating landfill leachate, participating in the anaerobic degradation process [42], representing one of the central communities in the urban waste leaching system.

Page $9 / 21$ 
The relative abundance of Fastidiosipila genera is alarming, as this group is pathogenic, found in blood and related to osteitis cases [43], and may indicate hospital wastes presence. The bioaerosol produced by a landfill is a dispersion vector of pathogens by air to other regions [44]. Bioaerosol emitted by municipal landfills is the source of hemolytic bacteria and pathogenic bacteria, including Pseudomonas aeruginosa and Bacillus subtilis [45]. As the leachate is stored in the open air, it could be a pathogen source to the atmosphere.

Almost half of the sample diversity had less than $1 \%$ of the frequency (supplementary material). This low-abundance diversity may work as a microorganism pool, and as the leachate composition changes, they become dominant [46]. Analysis performed in different microbiomes (rhizosphere of different perennial grassland species) showed that low-abundance bacteria action presented specific responses to a given metabolic process [47]. However, high bacterial diversity levels presume that several taxons are redundant concerning the function [48].

In the study of Yang and Song [27], Prevotella and Sphingobacterium were more abundant at the methanogenic phase. And, although the chemical-physical parameters indicate a methanogenic phase profile in our leachate, the metabarcoding showed the absence of this group in our work. As the leachate reservoirs receive an influx of all MSW cells, methanogenic groups are likely inhibited by the leachate of cell 3 that containing a high organic matter level compared to the older cells. On the opposite, it is highly likely that methanogenic groups dominate cells 1 and 2 . Besides, the sample was collected in a shallow depth, which is another factor that explains the low abundance of methanogenic groups. Also, the primers used in the sequencing method are known to not be specific for amplifying methanogens. Thus, the lower abundance may be due to methodological bias rather than ecologic reasons [31].

Regarding the Archaea diversity despite not being the study's focus, it was possible to identify the Methanosarcina, $(0.142 \%)$, Methanospirillum $(0.101 \%)$, Methanosaeta $(0.089 \%)$, Methanothermobacter $(0.032 \%)$, and Methanoculleus $(0.028 \%)$. All genera were also observed in low-abundance [8] in leachate from Candeias landfill, except for Methanospirillum. Cardinali-Rezende et al. [49] identified hydrogenotrophic and methanogens archaea belonging to Methanomicrobiales and Methanobacteriales genera from the digestion process fed wastewater sludge and organic fraction of the municipal solid waste. Methanospirillum and Methanothermobacter can be considered one of the most common genera related to the hydrogenotrophic methanogens organism (produced methane from hydrogen and carbon dioxide), found in anaerobic digesters. On the other hand, the genera Methanosarcina, Methanospirillum, Methanosaeta can be considered one of the most common genera to acetoclastic methanogens (produced methane from acetic acid reduction), found in anaerobic digesters [50]. It was suggesting a considerable methanogenic diversity in our sample, responsible for methane production. That corroborated with the chemical data (mixed characteristics of the acidic and methanogenic phases). However, this diversity was represented by a low abundance of these genera. Thus, prevailing the anaerobic digestion concerning organic waste by the dominant genera from phylum Firmicutes. 
Although toxic contaminants in leachate, including dissolved organic matter, heavy metals and organic xenobiotic compounds may have influenced the microbial composition in the samples studied [51]. Our study is essential, since it was possible to observe a considerable microbial community related to pathogenic taxonomic groups, indicating care with potential leaks and environmental contamination. As well as taxonomic groups possibly involved in bioremediation processes.

The use of microbial communities recovered from the landfill itself in bioremediation processes can be regarded as a useful tool in replacing of conventional methods (as physical-chemical approaches). Since biological treatment, including bioremediation approaches, it may often be preferred due to its reliability, low operating costs, and simplicity providing several advantages about the biodegradable matter and nitrogen compound removal [52].

The bacterial community can be resistant to a wide range of compounds found in leachate samples, and it may have a high potential application for its treatment [53]. The majority of environmental microbiomes is not amenable to cultivation under standard laboratory growth conditions and hence remain uncharacterized. For environmental applications, such as bioremediation, it is necessary to isolate microbes performing the desired function, which may not necessarily be the fast growing or the copiotroph microbiota [9]. So, from our project, a bioremediation process can be designed based on the recent strategic known as culturomics, where enriched culture media can be developed to recover the main genera identified in our studies, which may be involved in leachate bioremediation processes. This strategy aims to improve cultivation efficiencies of environmental microbiota and can be coupled application of omics-based tools [54].

Lastly, to our knowledge, the present study can be characterized as one of the first studies on the microbial diversity of leachate in the stabilization phase with a recirculation system. More studies are needed to understand the microbial diversity of leachate in different scenarios, with and without recirculation, and in different phases. The results emphasize the need for regular monitoring of microbiological and encourage future studies on the use of microbial communities recovered from leachate. Further analysis using metatranscriptomics and/or metagenomics approaches must to be done to help elucidate ecologic functionality, and allow a targeted search for taxa and/or genes that are capable to biotransforming toxic and recalcitrant compounds found in leachate.

\section{Conclusions}

The leachate stored in the sanitary landfill of Foz do Iguaçu city presents showed physical-chemical conditions, from both acid and methanogenic phases. This phenomenon is reflected in the prokaryotic community, with the phylum Firmicutes' predominance and genera from the aerobic and anaerobic phases. The aerobic group can act in the hydrolytic reactions, where the organic fraction can be metabolized aerobically to form $\mathrm{CO}_{2}$ and $\mathrm{H}_{2} \mathrm{O}$. Also, bacteria from the anaerobic phase are characterized by fermentation, generating organic acids, and ammoniacal nitrogen. In addition, was observed that the leachate acidogenic phase ended up being masked in the chemical and physical analyzes, but was 
evidenced in the metabarcoding methodology. The concentration of ammoniacal nitrogen was below average, which indicate the action of the methanogenic phase. However, no specifically methanogenic group was detected in significant abundance. Several factors may have contributed to the absence of methanogenics. As one of the first studies that analyze leachate from landfill considered old and with recirculation, it is possible to conclude that these results were due to the effect of the leachate recirculation between the MSV systems cells. And although the physical-chemistry parameters indicate good degradability, further investigations are necessary to confirm the recirculation system efficiency.

Functionally, microorganisms involved with the carbon, nitrogen, and sulfur cycle were detected, mainly. Those groups have a crucial role in the development of bioremediation strategies towards toxic leachate compounds. As considered an extreme environment, the sample presented several microbial groups able to develop even under toxic conditions. Even though the biodegradation efficiency showed by physicalchemistry analysis, the recirculation may result in the accumulation of cations, especially cadmium. Pseudomonas aeruginosa showed significant relative abundance and can be explored by culturomics studies for bioremediation applications.

\section{Declarations}

\section{Funding}

This work was supported by the Institutional Program Triple Agenda EDITAL PRPPG N 137/2018 UNILA.

\section{Conflicts of interest/Competing interests}

The authors declare that they have no competing interests

\section{Availability of data and material}

The datasets generated during the current study are available in the Rafaella Santos repository, https://basespace.illumina.com/projects/143361223 . Reference number 2-DNA-CH-16S.

\section{Code availability}

Not applicable

\section{Ethics approval}

Not applicable

\section{Consent for publication}

Not applicable

\section{Authors' contributions}


MRZP: formal analysis, Funding acquisition, Project administration, Supervision, Visualization, Writing original draft, Writing - review \& editing. JVFM: formal analysis, Metodology. JAMG: formal analysis, Metodology. RCB-S: formal analysis, Funding acquisition, Project administration, Supervision, Visualization, Writing - original draft, Writing - review \& editing.

\section{Acknowledgements}

We want to thank UNILA for the facilities to develop our projects.

\section{References}

[1] Palermo GC, Gomes APP (2017) Tratamento e gestão de resíduos. First ed. UVA, Rio de Janeiro.

[2] Kjeldsen P, Barlaz MA, Rooker AP, Baun A, Ledin A, Christensen TH (2002) Present and long-term composition of MSW landfill leachate: A review. Crit Rev Environ Sci Technol 32:297-336.

$10.1080 / 10643380290813462$

[3] Di laconi C, Ramadori R, Lopez A (2006) Combined biological and chemical degradation for treating a mature municipal landfill leachate. Biochem. Eng J 31:118-124.

https://doi.org/10.1016/j.bej.2006.06.002

[4] Christensen TH, Kjeldsen P, Bjerg PL, Jensen DL, Christensen JB, Baun A, Albrechtsen H-J, Heron G (2001) Biogeochemistry of landfill leachate plumes. Appl Geochem 16:659-718.

https://doi.org/10.1016/S0883-2927(00)00082-2

[5] Santos A, van Aerle R, Barrientos L, Martinez-Urtaza J (2020) Computational methods for $16 \mathrm{~S}$ metabarcoding studies using Nanopore sequencing data. Comput Struct Biotec 18:296-305. https://doi.org/10.1016/j.csbj.2020.01.005

[6] Weaver JE, Wang L, de los Reyes III FL, Barlaz MA (2019) Systems and methods for studying microbial processes and communities in landfills. In: Hurst CJ (ed) Understanding terrestrial microbial communities. Springer, Cham, pp 129-150

[7] Kurniawan TA, Lo WH, Chan GYS (2006) Physico-chemical treatments for removal of recalcitrant contaminants from landfill leachate. J Hazard Mater B129:80-100.

https://doi.org/10.1016/j.jhazmat.2005.08.010.

[8] Köchling T, Sanz JL, Gavazza S, Florencio L (2015) Analysis of microbial community structure and composition in leachates from a young landfill by 454 pyrosequencing. Appl Microbiol Biotechnol 13:5657-5668. https://doi.org/10.1007/s00253-015-6409-4

[9] Pathak A, Jaswal R, Xiaoyu X, White JR, Edwards B, Hunt J, Brooks S, Rathore RS, Agarwal M, Chauhan $A$ (2020) Characterization of bacterial and fungal assemblages from historically contaminated 
metalliferous soils using metagenomics coupled with diffusion chambers and microbial traps. Front Microbiol 11. https://doi.org /10.3389/fmicb.2020.01024

[10] Klindworth A, Pruesse E, Schweer T, Peplies J, Quast C, Horn M, Glöckner FO (2013) Evaluation of general $16 \mathrm{~S}$ ribosomal RNA gene PCR primers for classical and next-generation sequencing-based diversity studies. Nucleic Acids Res 41:e1. https://doi.org/10.1093/nar/gks808

[11] Bolyen E, Rideout JR, Dillon MR et al (2018) QIIME 2: Reproducible, interactive, scalable, and extensible microbiome data science. Peer J Prep 6:e27295v2.

https://doi.org/10.7287/peerj.preprints.27295v2

[12] Afgan E, Baker D, Batut B, van den Beek M, Bouvier D, Cech M, Chilton J, Clements D, Coraor N, Gruning BA, Guerler A, Hillman-Jackson J, Hilteman S, Jalili V, Rasche H, Soranzo N, Goecks L, Taylor J, Nekrutenko A, Blankenberg D (2018) The Galaxy platform for accessible, reproducible and collaborative biomedical analyses: 2018 update. Nucleic Acid Res 46: W537-W544. https://doi.org/doi:

10.1093/nar/gky379

[13] Quast C, Pruesse E, Yilmaz P, Gerken J, Schweer T, Yarza P, Peplies J, Glockner FO (2013) The SILVA ribosomal RNA gene database project: improved data processing and web-based tools. Nucleic Acids Res 41:D590-D596. https://doi.org/doi: 10.1093/nar/gks1219

[14] Adhikari B, Khanal SN, Lamichhane J, Giri D (2014) Seasonal variation of pH, BOD, COD and BOD/COD ratio in different ages of landfill leachate in Nepal. J Biomol Reconst 11:89-99.

[15] CONSELHO NACIONAL DO MEIO AMBIENTE - CONAMA 430 (2011) Condições e padrões de lançamento de efluentes. https://www.legisweb.com.br/legislacao/?id=114770. Accessed 24 July 2020

[16] Top S, Akkaya GK, Demir A et al (2019) Investigation of leachate characteristics in field-scale landfill test cells. Int J Environ Res 13:829-842. 10.1007/s41742-019-00217-510.1007/s41742-019-00217-5

[17] Pohland FG (1980) Leachate recycles as a landfill management option, J Environ. Eng. 106:10571069.

[18] Hernández-Berriel MC, Mañón-Salas C, Sánchez-Yáñez JM, Lugo-de la Fuente J, Márquez-Benavides $L$ (2010) Influence of recycling different leachate volumes on refuse anaerobic degradation. The Open Waste Manag J 3: 155-166. 10.2174/1875934301003010155

[19] Marttinen SK, Kettunen RH, Sormunen KM, Soimasuo RM, Rintal JA (2002) Screening of physicalchemical methods for removal of organic material, nitrogen and toxicity from low strength landfill leachates. Chemosphere 46: 851-858. https://doi.org/10.1016/S0045-6535(01)00150-3

[20] Talalaj IA, Biedka P, Bartkowska I (2019) Tretment of landfill leachates with biological pretreatments and reverse osmosis. Environ Chem Lett 17:1177-1193. https://doi.org/10.1007/s10311-019-00860-6 
[21] Šan I, Onay TT (2001) Impact of various leachate recirculation regimes on municipal solid waste degradation. J Hazard Mater 87: 1-3. 10.1016/s0304-3894(01)00290-4

[22] Bilgili MS, Demir A, Özkaya B (2007) Influence of leachate recirculation on aerobic and anaerobic decomposition of solid wastes. J Hazard Mater 143: 1-2. https://doi.org/10.1016/j.jhazmat.2006.09.012

[23] Gabarró J, Amo EH-D, Gich F, Ruscalleda M, Balaguer MD, Colprim J (2013) Nitrous oxide reduction genetic potential from the microbial community of an intermittently aerated partial nitritation SBR treating mature landfill leachate. Water Res 47:7066-7077, 2013. 10.1016/j.watres.2013.07.057

[24] Bernhard, A (2010) The nitrogen cycle: Processes, players, and human impact. Nature Education Knowledge 2:12

[25] Kaczorek, K, Ledakowicz S (2006) Kinetics of nitrogen removal from sanitary landfill leachate. Bioprocess Biosyst Eng 29: 291-304. https://doi.org/10.1007/s00449-006-0078-8

[26] Ganigué R, López H, Balaguer MD, Colprim J (2007) Partial ammonium oxidation to nitrite of high ammonium content urban landfill leachates. Water Res 41: 3317-3326.

https://doi.org/10.1016/j.watres.2007.04.027

[27] Yang S, Song L (2019) Succession of bacterial community structure and metabolic function during solid waste decomposition. Bioresour Technol 291:121865.

https://doi.org/10.1016/j.biortech.2019.121865

[28] Costa MA, Alfaia RGDMS, Campos J (2019) Landfill leachate treatment in Brazil - An overview. J Environ Manage 232:110-116. 10.1016/j.jenvman.2018.11.006

[29] Badiye A, Kapoor N, Khajuria H (2013) Copper Toxicity: A Comprehensive Study. Res J Recent Sci 2:58-67.

[30] Dao HTN, Kuroda K, Nakahara N, Danshita T, Hatamoto M, Yamaguchi T (2016) 16S rRNA genebased comprehensive analysis of microbial community compositions in a full-scale leachate treatment system. J Biosci Bioeng 122:708-715. https://doi.org/10.1016/j.jbiosc.2016.06.003

[31] Bahram M., Anslan S, Hildebrand F, Bork P, Tedersoo L (2019) Newly designed 16S rRNA metabarcoding primers amplify diverse and novel archaeal taxa from the environment. Environ Microbiol Rep 11:487-494. https://doi.org/10.1111/1758-2229.12684

[32] Luo L, Wong JWC (2019) Enhanced food waste degradation in integrated two-phase anaerobic digestion: Effect of leachate recirculation ratio. Bioresour Technol 291.

https://doi.org/10.1016/j.biortech.2019.121813

[33] Kurtbóke D (2017) Ecology and habitat distribution of Actinobacteria. In: Wink J Mohammadipanah F, Hamed J (Eds) Biology and Biotechnology of Actinobacteria. Springer, Cham, pp 123-149 
[34] Winded C, Anneser B, Griebler C, Meckenstock RU, Lueders T (2008) Depth-resolved quantification of anaerobic toluene degraders and aquifer microbial community patterns in distinct redox zones of a tar oil contaminant plume. Appl Environ Microbiol 74:792-801. https://doi.org/10.1128/AEM.01951-07

[35] Madigan MT, Bender KS, Buckley DH, Sattley MW, StahI DA (2018) Brock biology of microrganisms. 15th ed, Pearson.

[36] Yang L, Wang X-H, Cui S, Ren Y-X, Yuc J, Chen N, Xiao Q, Guo L-K, Wang R-H (2019) Simultaneous removal of nitrogen and phosphorous by heterotrophic nitrification-aerobic denitrification of a metal resistant bacterium Pseudomonas putida strain NP5. Bioresour Technol 285:121360. https://doi.org/10.1016/j.biortech.2019.121360

[37] Chellaiah ER (2018) Cadmium (heavy metals) bioremediation by Pseudomonas aeruginosa: a minireview. Appl Water Sci 8. https://doi.org/10.1007/s13201-018-0796-5

[38] Rahimzadeh MR, Rahimzadeh MR, Kazemi S, Moghadamnia AA (2017) Cadmium toxicity and treatment: An update. Caspian J Intern Med 8:135-145. https://doi.org/10.22088/cjim.8.3.135

[39] Krieg NR, Ludwing W, Whitman W, Hedlund BP, Paser BJ, Staley JT, Ward N, Brown D (2010) Bergey's Manual of Systematic Bacteriology Vol. 4: The Bacteroidetes, Spirochaetes, Tenericutes (Mollicutes), Acidobacteria, Fibrobacteres, Fusobacteria, Dictyoglomi, Gemmatimonadetes, Lentisphaerae, Verrucomicrobia, Chlamydiae, and Planctomycetes, Springer, New York.

[40] Long Y, Fang Y, Shen D, Feng H, Chen T (2016) Hydrogen sulfide (H2S) emission control by aerobic sulfate reduction in landfill. Sci Rep 6:38103. https://doi.org/10.1038/srep38103

[41] Hugenholtz P, Hooper SD, Kyrpides NC (2009) Focus: Synergistetes. Environ Microbiol 11:1327-1329. https://doi.org/10.1111/j.1462-2920.2009.01949.x

[42] Mnif S, Zayen A, Karray F, Bru-Adan V, Louki S, Godon JJ, Chamkha M, Sayadi S (2012) Microbial population changes in anaerobic membrane bioreactor treating landfill leachate monitored by singlestrand conformation polymorphism analysis of 16S rDNA gene fragments. Int Biodeter Biodegr 73:50-59. https://doi.org/10.1016/j.ibiod.2012.04.014

[43] Beauruelle C, Bars HL, Pougnet L, Lesecq L, Buisson P, Héry-Arnauf G (2014) First human case of Fastidiosipila sanguinis infection. J Clin Microbiol 52:2713-2715. https://doi.org/10.1128/JCM.0046114

[44] Kaźmierczuk M, Bojanowicz-Bablok A (2014) Bioaerosol concentration in the air surrounding municipal solid waste landfill. Ochrona Środowiska i Zasobów Naturalnych - Environmental Protection and Natural Resources 25:17-25. https://doi.org/10.2478/oszn-2014-0015

[45] Kalwasinska A, Burkowska A (2013) Municipal landfill sites as sources of microorganisms potentially pathogenic to humans. Environ. Sci Processes Impacts 15:1078-1086. 
[46] Wittebolle L, Vervaeren H, Verstraete W, Boon N (2008) Quantifying community dynamics of nitrifiers in functionally stable reactors. Appl Environ Microbiol 74:286-293. https://doi.org/10.1128/AEM.0100607

[47] Dawson W, Hor J, Egert M, van Kleunen M, Pester M (2017) A small number of low-abundance bacteria dominate plant species-specific responses during rhizosphere colonization. Front Microbiol 8:975. https://doi.org10.3389/fmicb.2017.00975

[48] Rivett DW, Bell T (2018) Abundance determines the functional role of bacterial phylotypes in complex communities. Nat Microbiol 3:767-772. https://doi.org/10.1038/s41564-018-0180-0

[49] Cardinali-Rezende J, Debarry RB, Colturato LFDB, Carneiro EV, Chartone-Souza E, Nascimento AMA (2009) Molecular identification and dynamics of microbial communities in reactor treating organic household waste. Appl Microbiol Biot 84:777-789. https://doi.org/10.1007/s00253-009-2071-z

[50] Czatzkowska M, Harnisz M, Korzeniewska E, Koniuszewska I (2020) Inhibitors of the methane fermentation process with particular emphasis on the microbiological aspect: A review. Energy Sci Eng 11:1880-1897. https://doi.org/10.1002/ese3.609

[51] Zegzouti Y, Boutafda A, Fels LE, Hadek ME, Ndoye F, Mbaye N, Kouisni L, Hafidi M (2020) Screening and selection of autochthonous fungi from leachate contaminated-soil for bioremediation of different types of leachate. Environ Eng Res 25:722-734. https://doi.org/10.4491/eer.2019.317

[52] Zveibil VZ (2001) Manual de gerenciamento integrado de resíduos sólidos. Ibam, Rio de Janeiro.

[53] Morris S, Garcia-Cabellos G, Enright D, Ryan D, Enright A-M (2018) Bioremediation of landfill leachate using isolated bacterial strains. Int J Environ Bioremediat Biodegrad 6:26-35.

https://doi.org/10.12691/ijebb-6-1-4

[54] Bodor A, Bounedjoum N, Vincze GE, Erdeiné K, Laczi AK, Bende G, Szilágyi A, Kovács T, Perei K, Rákhely G (2020) Challenges of unculturable bacteria: environmental perspectives. Rev Environ Sci Biotechnol 19:1-22. https://doi.org/10.1007/s11157-020-09522-4

\section{Figures}




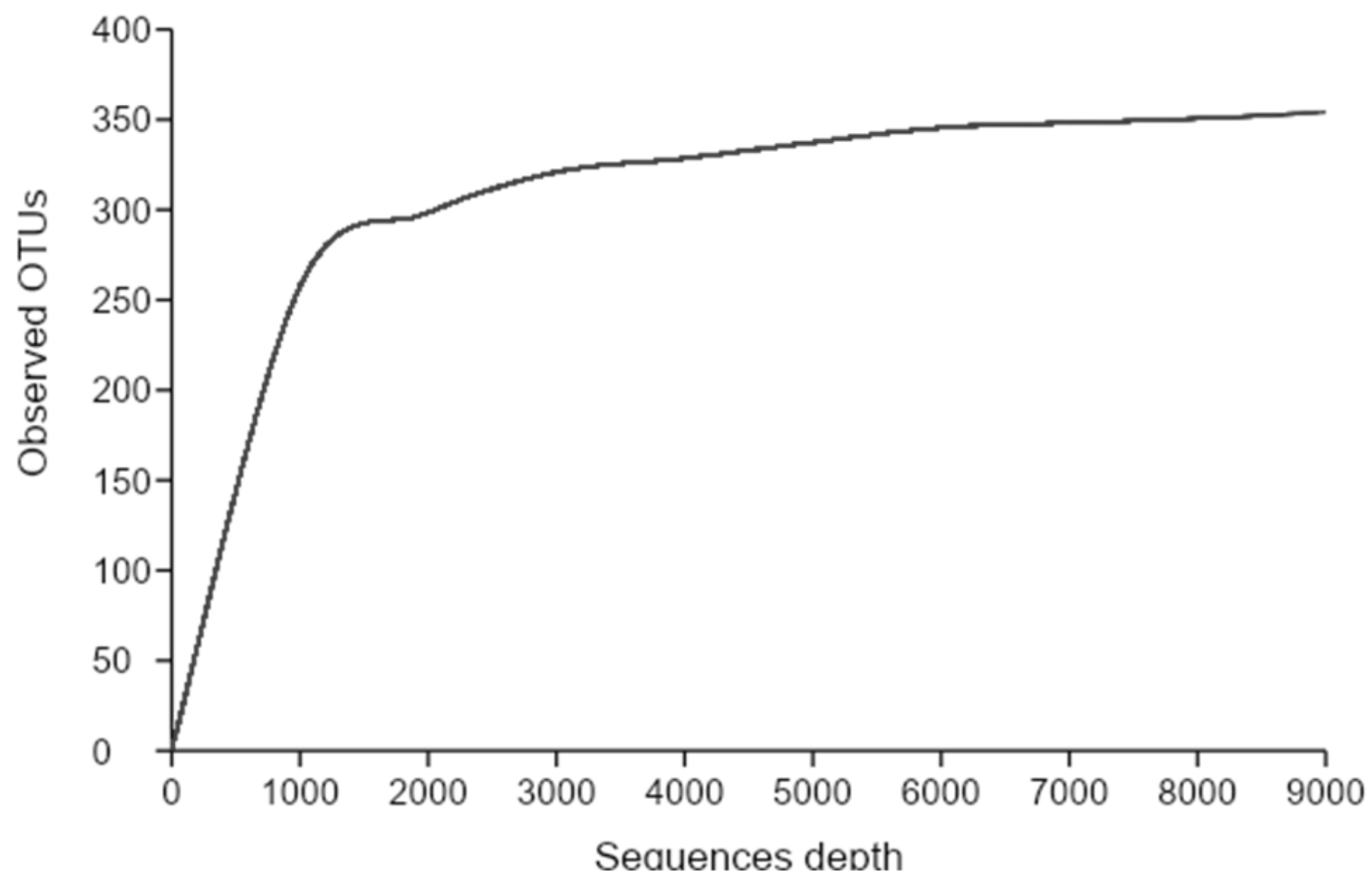

Figure 1

Rarefaction curve of the bacterial 16S rRNA gene sequences obtained using the metabarcoding method from leachate sampled in the sanitary landfill from Foz do Iguaçu, Paraná, Brazil. OTUs calculated at 99\% identity in the normalized dataset. The total number of sequences analyzed is plotted against the number of OTUs observed in the same library. 


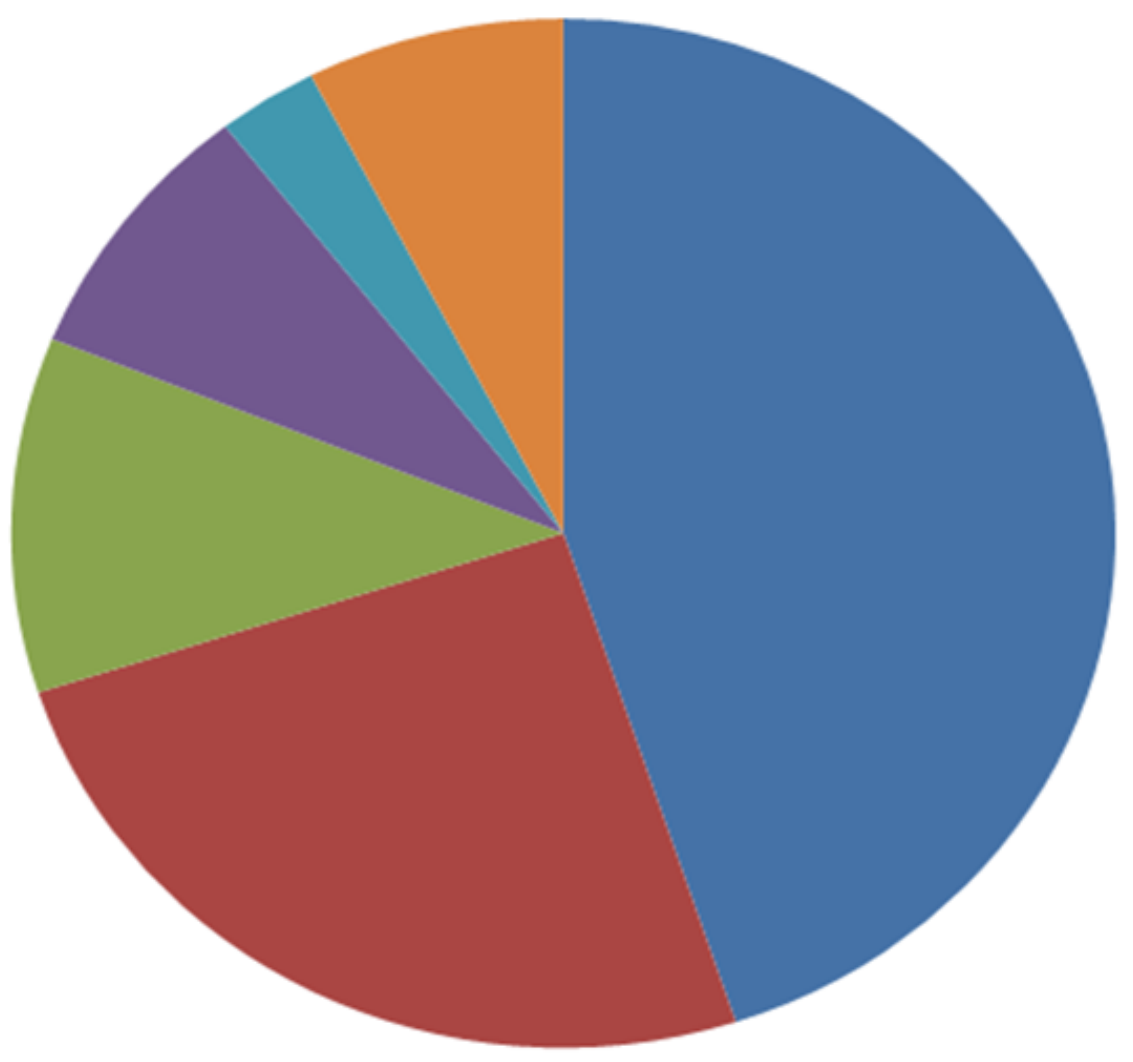

- Firmicutes

- Proteobacteria

Bacteroidetes

- Synergistetes

- Actinobacteria

Others

\section{Figure 2}

Main bacterial phyla obtained using the metabarcoding method from leachate sampled in the sanitary landfill from Foz do Iguaçu, Paraná, Brazil. 


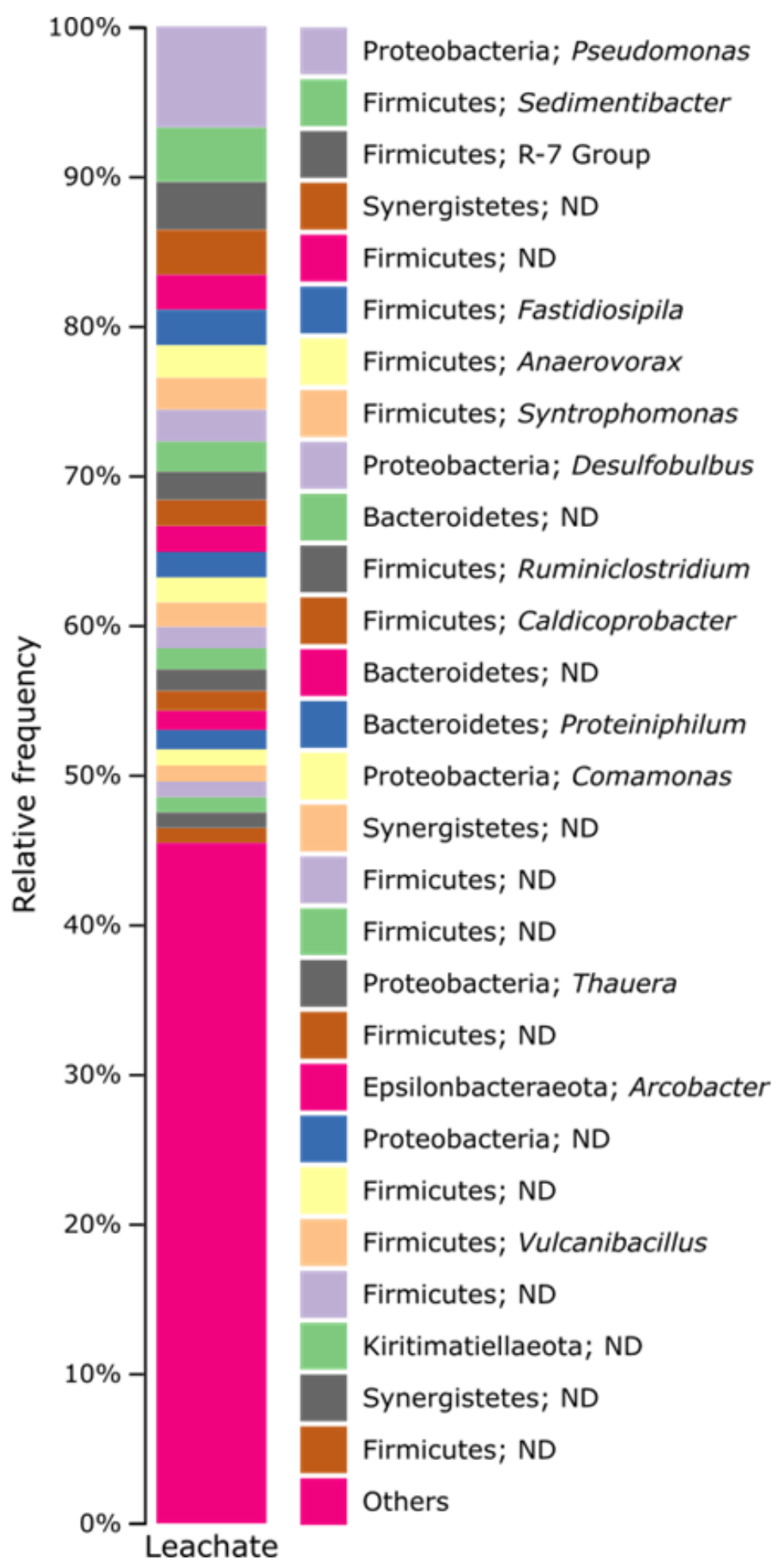

\section{Figure 3}

Dominant genera with relative frequency higher than $1 \%$ obtained using the metabarcoding method from leachate sampled in the sanitary landfill from Foz do Iguaçu, Paraná, Brazil the leachate sample.

\section{Supplementary Files}


This is a list of supplementary files associated with this preprint. Click to download.

- Supplementarymaterial.doc 